\title{
Site fidelity and movement of adult Atlantic cod Gadus morhua at deep boulder reefs in the western Gulf of Maine, USA
}

\author{
James Lindholm ${ }^{1,3, *}$, Peter J. Auster ${ }^{1}$, Ashley Knight ${ }^{2}$ \\ ${ }^{1}$ National Undersea Research Center and Department of Marine Sciences, University of Connecticut at Avery Point, \\ 1080 Shennecossett Rd., Groton, Connecticut 06340, USA \\ ${ }^{2}$ Pfleger Institute of Environmental Research, 901-B Pier View Way, Oceanside, California 92054, USA \\ ${ }^{3}$ Present address: Division of Science and Environmental Policy, California State University Monterey Bay, \\ 100 Campus Center, Building 53, Seaside, California 93955, USA
}

\begin{abstract}
Little is known about the role that patterns of habitat selection play in mediating movement of Atlantic cod Gadus morhua, particularly in off-shore environments. We used acoustic telemetry to study the movement of adult cod tagged at deep boulder reefs (DBRs) in the western Gulf of Maine. The movement of 65 cod tagged with acoustic transmitters was monitored by acoustic receivers deployed on the seafloor at 4 DBRs from May to September 2002 and September 2004 to February 2005. Each receiver encompassed an area of the seafloor of approximately $0.5 \mathrm{~km}^{2}$, and data on each fish were recorded for up to $95 \mathrm{~d}$ post-release. Twenty-three cod (35.4\% of tagged fish) exhibited high site fidelity to the DBR where they were caught and released (recorded in $>82 \%$ of the $1 \mathrm{~h}$ time bins), while $33 \mathrm{cod}$ (50.8\% of tagged fish) appeared to depart the area rapidly following release (recorded in $<20 \%$ of the $1 \mathrm{~h}$ time bins). Cod with high site fidelity exhibited no pattern of diel activity. Cod movement among DBRs was recorded in both sampling periods (maximum linear distance of at least $24 \mathrm{~km}$ ). Patterns of site fidelity and movement did not differ significantly with fish total length, among individual DBRs, or between sampling periods. Understanding the spatial dynamics of fish populations with both resident and transient components that are linked to particular habitats can aid in development of unique management strategies for both sustainable fisheries and conservation of biological diversity.
\end{abstract}

KEY WORDS: Acoustic telemetry $\cdot$ Tagging $\cdot$ Behavior $\cdot$ Habitat

Resale or republication not permitted without written consent of the publisher

\section{INTRODUCTION}

Atlantic cod (family: Gadidae, Gadus morhua Linnaeus, 1758) is a demersal fish found throughout the North Atlantic, from the surface to a depth of $600 \mathrm{~m}$ (Collette \& Klein-McPhee 2002, Lear 1999). It feeds primarily on amphipods and shrimps when small and shifts to piscivory as size increases (Garrison \& Link 2000). In the NW Atlantic, cod populations in the Gulf of Maine (GoM) have been exploited for several hundred years (Serchuk \& Wigley 1992, Jackson et al. 2001), and are currently at extremely low population levels (Mayo \& Terciero 2005).
The movement of cod has been documented over a wide range of space and time scales using traditional tag/recapture approaches (summarized by Robichaud \& Rose 2004), acoustic telemetry (Clark \& Green 1990, Robichaud \& Rose 2001, Cote et al. 2002, 2004), and data storage tags (Neat et al. 2006). Tagging in the GoM has largely been conducted with traditional tag/recapture approaches (Hunt \& Neilson 1993, Perkins et al. 1997, Hunt et al. 1999). Results generally support the delineation of 4 regional populations (i.e. Georges Bank and Gulf of Maine, USA; Bay of Fundy and Scotian Shelf, Canada), with fish showing site fidelity across a gradient of spatial scales within 
regions as well as movement of individual animals among populations. However, there continues to be a paucity of data on the influence of local environmental conditions on the movement of cod (Cote et al. 2002, 2004, Neat et al. 2006). Little is known, for instance, about the role that patterns of habitat selectivity play in mediating movement, particularly in off-shore environments. A pilot study using acoustic telemetry in the western GoM showed that approximately one-third of tagged adult cod exhibited high site fidelity in a small $\left(0.5 \mathrm{~km}^{2}\right)$ area of low-relief, pebble/cobble habitat from late-spring through early-fall (Lindholm \& Auster 2003). Such behavior suggests that at least a portion of local populations orient to small-scale habitat features, and there is variation in the strength of habitat affinities between individuals. Models linking survivorship of cod to variations in habitat attributes indicate that the utility of habitat-specific conservation and management measures are highly sensitive to fish movement rates (Lindholm et al. 2001). Therefore, information on the movement patterns of key species relative to boundaries developed for spatial management approaches is vital for predicting outcomes that lead to conservation and sustainable use.

In the present study, we tagged adult cod with acoustic transmitters and released them on the seafloor at replicate deep boulder reefs (DBRs) in the western GoM. DBRs occur at 50 to $100 \mathrm{~m}$ depths where cod are common components of the fish community (Auster \& Lindholm 2005). Our primary goals were to determine: (1) variation in fish movement among individual DBRs and (2) any seasonal variation in fish movements relative to DBRs. We predicted that within-season variability in cod movement among individual DBRs would be low, while the variation in fish movement across seasons would be high.

\section{MATERIALS AND METHODS}

Four DBR sites were selected within the western Gulf of Maine closed area (a fishery closure), where it overlaps with the boundary of the Stellwagen Bank National Marine Sanctuary (SBNMS; Fig. 1). The closure has excluded all commercial fishing gear targeting demersal fishes since May 1998. Tagging in this area reduced, but did not entirely preclude, the probability of tagged fish being caught during the study as recreational hook-and-line fisheries were still allowed.

DBRs are discrete features composed of boulder size (i.e. minimum diameter of $256 \mathrm{~mm}$ ) rocks and are bounded by smaller diameter gravel, sand, or mud sediments (sensu Auster \& Lindholm 2005). A continuous-coverage multibeam sonar bathymetric and acoustic backscatter map of the seafloor (Valen- tine et al. 2003) allowed us to differentiate DBRs from surrounding low-relief habitats and select comparable sites based on depth. A remotely operated vehicle (ROV) was used to verify that structures identified from the map were indeed DBRs by definition and to insure comparable fish and epifaunal community structure at each station. Video inspection also allowed us to select similar sites for capturing and releasing fish and for deploying acoustic receivers.

All cod Gadus morhua were collected via hook and line. Fish were reeled in slowly to reduce barotrauma and thermal shock. Each fish was tagged externally in the dorsal musculature at the base of the first dorsal fin with a V8SC-1H-R256 coded transmitter (VEMCO) anchored using a T-bar tag. From the point of insertion, the transmitter extended toward the tail approximately $5 \mathrm{~cm}$, just to the left of the dorsal line. No differences in the behavior of individual tagged fish were observed in laboratory experiments (e.g. total number of turns per hour) when compared to fish that were not tagged (Lindholm unpubl. data), while field studies indicated that tag retention was essentially $100 \%$ over a 95 d study period (Lindholm \& Auster 2003). The transmitters were programmed to emit a unique identification code at random intervals every 60 to $180 \mathrm{~s}$. Following tagging, each fish was maintained briefly in a live well with fresh-flowing seawater to insure there was no visible trauma, such as external bleeding and difficulty swimming or holding station. Each fish was then placed in a fish release device (Lindholm \& Auster 2003) that was lowered to the seafloor by a winch and opened via triggering using a messenger. All fish were released on the seafloor between 11:00 and 22:00 h GMT at the location where they were captured.

The movement of tagged cod was monitored using 4 omni-directional, single-channel (69 kHz) VR2 acoustic receivers (VEMCO). A single VR2 receiver was placed near the center of each of the 4 DBRs at 60 to $65 \mathrm{~m}$ water depth (Fig. 1). Tests indicated that the range of detection for a tag in the study area was a radius of approximately $400 \mathrm{~m}$ (based on a detection efficiency of $80 \%$ using 2 transmitters at that distance), or an area of the seafloor equal to approximately $0.5 \mathrm{~km}^{2}$. Each receiver was anchored using a $261.3 \mathrm{~kg}$ railroad wheel and was supported $2 \mathrm{~m}$ above the seafloor using a single sub-surface float. Receivers were recovered via acoustic releases (Model 111, InterOcean Systems) attached between each receiver and anchor.

Data were collected over 2 sampling periods: May to September 2002 (i.e. spring to fall) and September 2004 to March 2005 (i.e. fall through winter). Data were collected for individual fish up to $390 \mathrm{~d}$. However, the projected battery life for each tag was only $95 \mathrm{~d}$, and we excluded data beyond that time due to uncer- 
tainties in the quality of the transmitted signal and the uncertainty of detecting tagged fish.

Thirty-eight fish $($ mean $=51 \mathrm{~cm}$ total length [TL]; $\mathrm{SD}=5.24$ ) were tagged between 20 May and 2 July 2002, and 27 fish $($ mean $=57 \mathrm{~cm} \mathrm{TL}$; SD $=15$ ) were tagged between 16 September and 27 November 2004. Fish length did not differ between DBRs within sample periods (ANOVA, $F_{3,34}=0.04$, $\mathrm{p}=0.988$ for $2002 ; F_{2,24}=0.53, \mathrm{p}=$ 0.598 for 2004). However, TL of fish in 2002 was significantly different from fish tagged in 2004 (ANOVA, $F_{1,63}=$ 4.13, $\mathrm{p}=0.046)$. We do not view this disparity in fish size as an impediment to comparing movement patterns from one period to the next as all tagged fish were adults. The acoustic receiver at DBR 3 was lost during the 2004 study period, and no data were collected on the 11 fish tagged there.

The recorded time at-large (the time period from the first record to the last record) was plotted for each tagged fish at each DBR in $24 \mathrm{~h}$ periods up to the 95 d lifetime of the transmitter battery or until the end of the study and varied for each fish depending on release date. Each $24 \mathrm{~h}$ period of a fish's time at-large was apportioned into 24 time bins of $1 \mathrm{~h}$, standardized across receivers. For example, Bin 1 occurred each day from 00:00:00 to 00:59:59 h, while Bin 24 occurred from 23:00:00 to 23:59:59 h. All signal detections for each fish were assigned to particular $1 \mathrm{~h}$ time bins. Solitary detections that were neither preceded nor followed by another detection within 59 min were deleted from the study to avoid the inclusion of 'phantom' detections.

The site fidelity of a tagged fish to a particular DBR was calculated as the total number of time bins in which the fish was recorded by a receiver divided by the total number of $1 \mathrm{~h}$ bins possible (up to a maximum of $2280 \mathrm{~h}$ ). Patterns of site fidelity were compared among the 4 DBRs within each sampling period using the Kruskal-Wallis test (Sokal \& Rohlf 1995). A 1-tailed Mann-Whitney test (Sokal \& Rohlf 1995) was used to test the hypothesis that site fidelity of fish would be higher during the summer months than in the winter months (i.e. between sampling periods). We defined high site fidelity as those fish recorded at a single DBR for $>80 \%$ of the potential $1 \mathrm{~h}$ time bins. However, there is no consensus in the literature on a precise definition of 'high' site fidelity when interpreting movement patterns from tagged fish in general or cod in particular. Robichaud \& Rose (2004) categorized $32 \%$ of cod groups as sedentary if they remained in an area as large as $18000 \mathrm{~km}^{2}$. Our characterization of high site fidelity to a particular seafloor feature (actually an area of $0.5 \mathrm{~km}^{2}$ ) at the scale of hours is more spatially refined and temporally 
conservative than previous studies for this species in the GoM region.

The frequency of departures from a receiver, as well as the mean and maximum duration of each departure, was calculated for fish exhibiting high site fidelity. A departure was defined by the absence of a fish for 1 or more consecutive $1 \mathrm{~h}$ bins, which was ultimately followed by a return of the fish to the range of the receiver. The total numbers of fish departures from a DBR were compared within and between sampling periods using 1-way ANOVAs. These data were normalized following log transformation. The duration of each departure was compared among DBRs within sampling periods using the Kruskal-Wallis test and between sampling periods using the Mann-Whitney test.

Diel patterns in fish movement were investigated by calculating the proportion of diurnal and nocturnal $1 \mathrm{~h}$ time bins in which each fish was recorded, weighted for the total number of hours of light and dark throughout the study period. To compare diel fish movements among DBRs within each sampling period and between sampling periods, a ratio of diurnal/nocturnal $1 \mathrm{~h}$ time bins was calculated. The Kruskal-Wallis test was used to compare this ratio among DBRs within each sampling period, while the Mann-Whitney test was used to compare the ratio between sampling periods. We used an alpha level of 0.05 for all tests.

\section{RESULTS}

\section{Spring to fall 2002}

The recorded number of days for Atlantic cod Gadus morhua at each DBR varied widely, ranging from 1 to $95 \mathrm{~d}$ (Fig. 2A). Six tagged cod were recorded at $>1$ DBR. One fish (Tag 34) was recorded at both DBR 1 and 4 on 3 separate days, a linear distance traveled of at least $24 \mathrm{~km}$, while 2 fish (Tags 25 and 26) traveled the $20 \mathrm{~km}$ between DBR 2 and 4 . The remaining 3 fish (Tags 2, 16, and 32) were recorded between reefs with
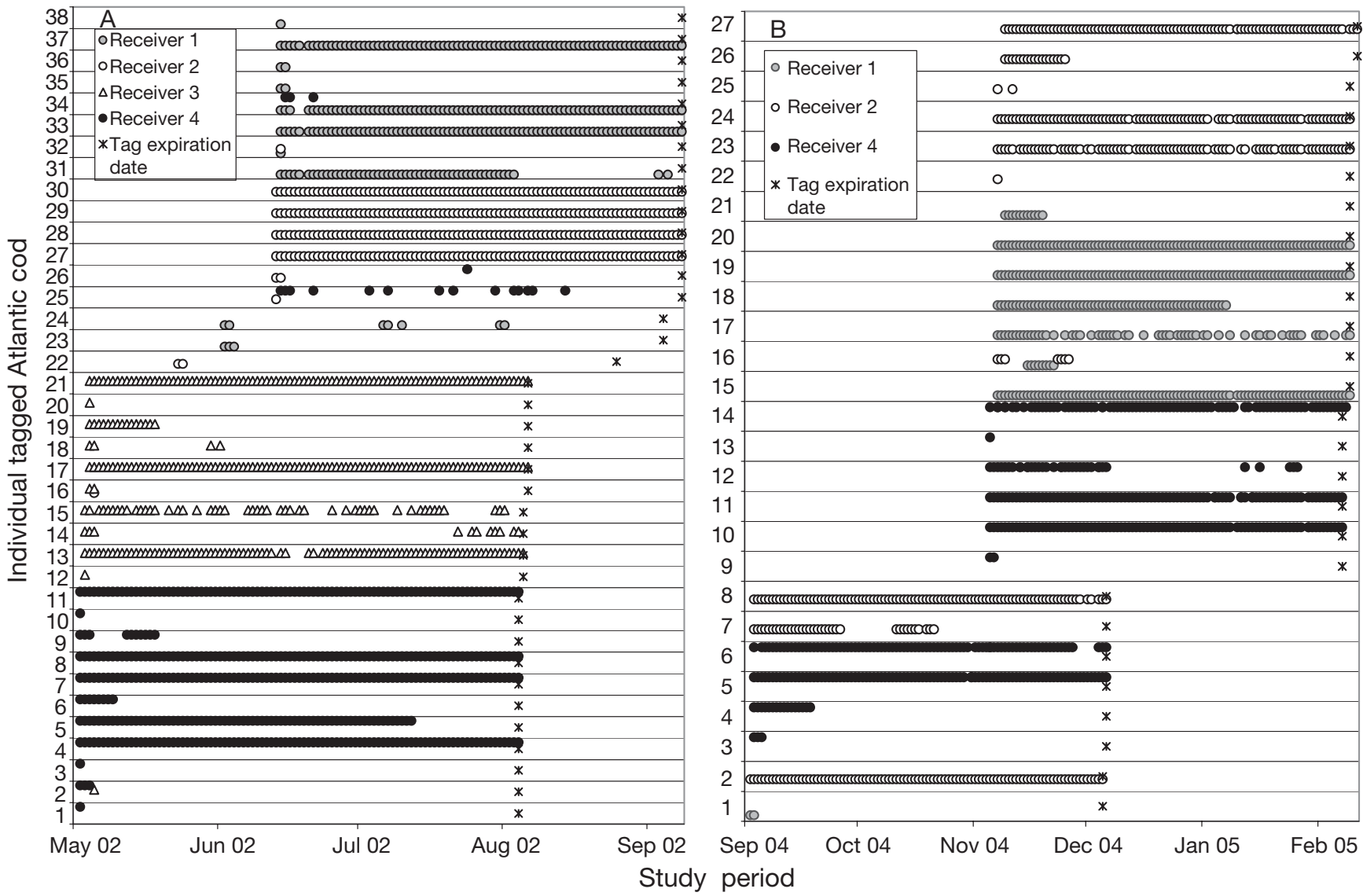

Fig. 2. Recorded time at-large for individual tagged Atlantic cod Gadus morhua released at deep boulder reefs (DBR): (A) a total of 38 fish monitored from 20 May through 26 September 2002 and (B) a total of 27 fish monitored from 14 September 2004 through 28 February 2005. Each symbol represents a day on which a fish was detected by a receiver, with shaded circles and triangles depicting each deep boulder reef (DBR) and crosses depicting the expiration date for each transmitter. Note: Receiver 3 was lost during the course of the study in 2004/2005, and no data were collected for the fish released at that location 
Table 1. Site fidelity of Atlantic cod Gadus morhua tagged in 2002 and 2004, expressed as a percentage of the total $1 \mathrm{~h}$ time bins in which fish were recorded at each deep boulder reef (DBR)

\begin{tabular}{|lccc|}
\hline & \multicolumn{3}{c|}{ Site fidelity } \\
\cline { 2 - 4 } & $<20 \%$ & $21-79 \%$ & $80-100 \%$ \\
\hline $\mathbf{2 0 0 2}$ & & & \\
DBR 1 & 6 & 1 & 3 \\
DBR 2 & 3 & - & 4 \\
DBR 3 & 7 & 1 & 2 \\
DBR 4 & 6 & 1 & 4 \\
Total no. & 22 & 3 & 13 \\
(\%) & $(57.8)$ & $(7.8)$ & $(34.2)$ \\
2004 & & & \\
DBR 1 & 3 & 2 & 3 \\
DBR 2 & 3 & 3 & 4 \\
DBR 4 & 5 & 1 & 10 \\
Total no. & 11 & 6 & $(37.0)$ \\
(\%) & $(40.7)$ & $(22.2)$ & \\
\hline
\end{tabular}

minimum linear movement distances of $15.5,4$, and $5.5 \mathrm{~km}$, respectively.

The site fidelity of tagged cod varied widely (Table 1). Twenty-two fish were recorded at 1 or more DBRs for $<20 \%$ of the total $1 \mathrm{~h}$ bins. However, 13 fish (34.2\% of tagged fish) were recorded at the DBR of their release for $>82 \%$ of the total time. With the exception of Tag 34, which was recorded at both DBR 1 and 4, the majority of fish exhibiting high site fidelity to the DBR of their release were recorded only at that site. There were no significant differences in the proportion of fish exhibiting high site fidelity among all fish released at each of the 4 DBRs (Kruskal-Wallis, $H_{3}=3.39, \mathrm{p}=0.335$ ).

Each of the fish that exhibited high site fidelity (12 fish excluding Tag 34) made at least 1 departure from the range of the receiver where it was released (Table 2). In each case, departures were generally $2 \mathrm{~h}$ or less in duration. A comparison of the number of departures for these fish among the 4 DBRs indicated no significant differences (ANOVA, $F_{3,9}=1.16, \mathrm{p}=0.374$ ). The maximum duration of fish departures ranged from 1 to $36 \mathrm{~h}$ (Table 2), while the mean duration per departure was $1.4 \mathrm{~h}(\mathrm{SD}=0.27)$. A comparison of the mean hours per departure among DBRs indicated no differences (Kruskal-Wallis, $H_{3}=1.48, \mathrm{p}=0.687$ ).

Tagged cod did not exhibit clear diurnal movement patterns during this sampling period (Fig. 3A). Movements of a majority of fish (21 ind.) were evenly distributed between day and night. This was also the case for the 13 fish recorded most frequently, where the proportion of $1 \mathrm{~h}$ time bins recorded during daylight (mean $=0.483)$ and night $($ mean $=0.517)$ was comparable. Seven fish were recorded only during daylight hours, though none of those fish was recorded for $>2 \mathrm{~d}$ during the study period. No fish were recorded solely during the night hours. A comparison of the day/night detection ratio among the 4 receivers indicated no differences in diel movement patterns at each of the 4 DBRs (Kruskal-Wallis, $H_{3}=0.79, \mathrm{p}=0.853$ ).

\section{Fall 2004 to winter 2005}

The recorded number of days varied widely among fish, ranging from 1 to $95 \mathrm{~d}$ (Fig. 2B), as in the previous tagging period. One fish (Tag 16) was recorded at both DBR 1 and 2, a linear distance traveled of at least $4 \mathrm{~km}$.

The site fidelity of tagged cod to DBRs also varied widely (Table 1). Eleven fish $(40.7 \%$ of tagged fish) were recorded at 1 or more DBRs for $<20 \%$ of the total possible $1 \mathrm{~h}$ bins in the study. However, 10 fish $(37 \%$ of all tagged fish) were recorded at the DBR of their release for $>82 \%$ of the total possible $1 \mathrm{~h}$ bins in the study. Each of the tagged cod exhibiting high site fidelity to the DBR of its release was recorded only at that site. A comparison of site fidelity among the fish released at each of the 3 DBRs indicated no differences (Kruskal-Wallis, $H_{2}=0.11, \mathrm{p}=0.947$ ).

Table 2. Frequency of consecutive $1 \mathrm{~h}$ time bins in which no detection was recorded for tagged Atlantic cod Gadus morhua exhibiting high site fidelity to DBRs in 2002 and 2004/2005, and the maximum hours departed for each fish. Fish 34 showed high site fidelity but was not included in this table as it was detected at $>1$ DBR (see 'Results')

\begin{tabular}{|c|c|c|c|c|c|c|c|}
\hline \multirow{2}{*}{$\begin{array}{l}\text { Fish } \\
\text { no. }\end{array}$} & \multicolumn{6}{|c|}{ Departures of: } & \multirow{2}{*}{$\begin{array}{c}\text { Max. hours } \\
\text { departed }\end{array}$} \\
\hline & $1 \mathrm{~h}$ & $2 \mathrm{~h}$ & $3 \mathrm{~h}$ & $4 \mathrm{~h}$ & $5 \mathrm{~h}$ & $5+\mathrm{h}$ & \\
\hline \multicolumn{8}{|l|}{2002} \\
\hline 4 & 22 & 6 & 3 & 3 & 0 & 3 & 16 \\
\hline 7 & 23 & 2 & 6 & 0 & 2 & 6 & 12 \\
\hline 8 & 46 & 12 & 6 & 2 & 4 & 12 & 19 \\
\hline 11 & 1 & 0 & 0 & 0 & 0 & 0 & 1 \\
\hline 17 & 8 & 2 & 1 & 2 & 0 & 0 & 4 \\
\hline 21 & 25 & 1 & 2 & 0 & 0 & 0 & 3 \\
\hline 27 & 2 & 0 & 1 & 0 & 0 & 0 & 3 \\
\hline 28 & 7 & 1 & 0 & 0 & 0 & 1 & 8 \\
\hline 29 & 6 & 2 & 1 & 0 & 0 & 1 & 9 \\
\hline 30 & 10 & 2 & 1 & 0 & 0 & 2 & 10 \\
\hline 33 & 16 & 6 & 1 & 3 & 1 & 10 & 35 \\
\hline 37 & 30 & 7 & 5 & 3 & 2 & 5 & 36 \\
\hline \multicolumn{8}{|l|}{2004} \\
\hline 2 & 33 & 7 & 4 & 3 & 4 & 6 & 12 \\
\hline 5 & 0 & 0 & 0 & 0 & 0 & 1 & 15 \\
\hline 6 & 36 & 9 & 8 & 6 & 5 & 13 & 151 \\
\hline 8 & 18 & 6 & 5 & 4 & 4 & 17 & 36 \\
\hline 10 & 9 & 4 & 2 & 1 & 2 & 4 & 33 \\
\hline 11 & 28 & 13 & 5 & 2 & 2 & 13 & 39 \\
\hline 15 & 34 & 13 & 4 & 5 & 3 & 16 & 36 \\
\hline 19 & 8 & 2 & 0 & 0 & 0 & 0 & 2 \\
\hline 20 & 6 & 1 & 0 & 1 & 0 & 0 & 4 \\
\hline 27 & 6 & 0 & 0 & 0 & 0 & 0 & 1 \\
\hline
\end{tabular}




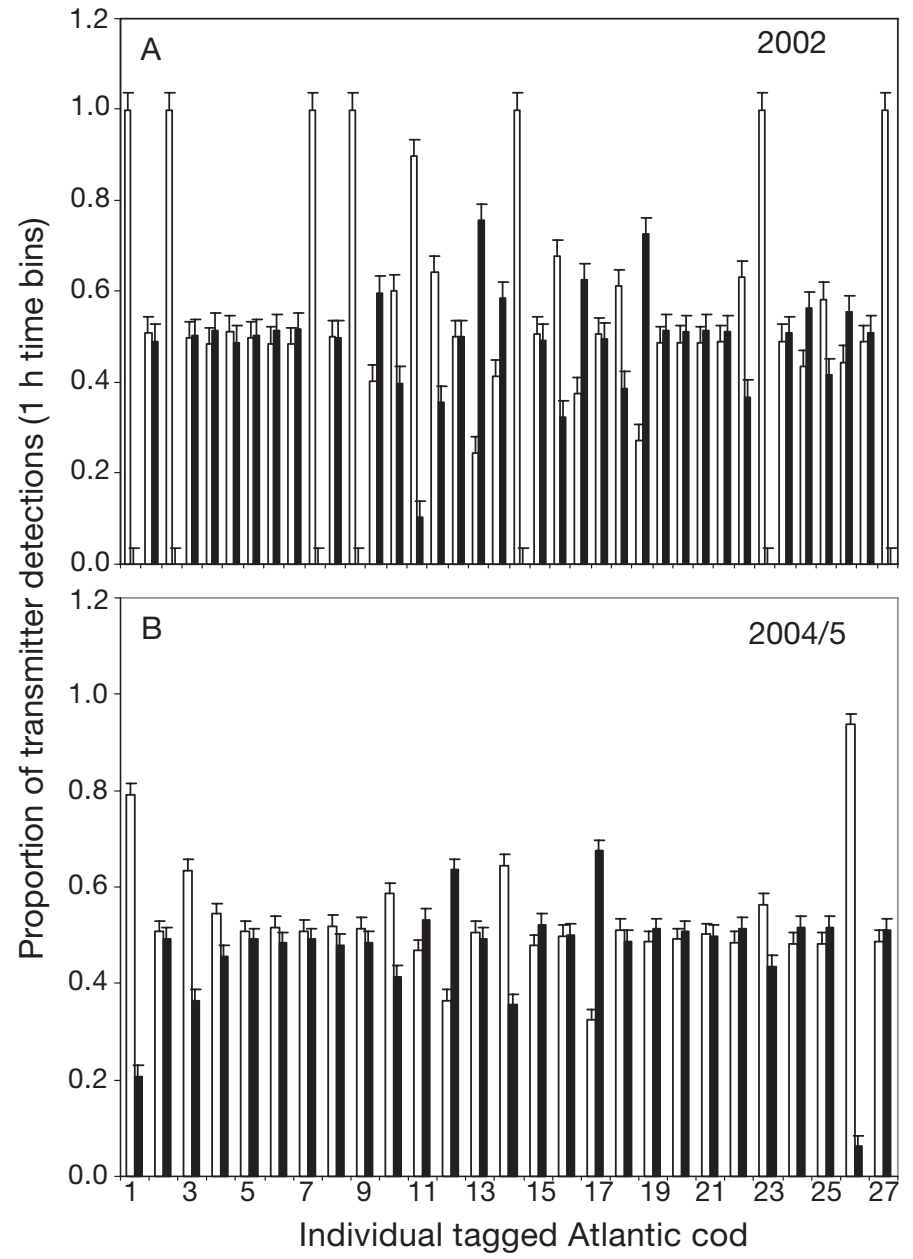

Fig. 3. Proportion of diurnal (white) and nocturnal (black) transmitter detections ( $1 \mathrm{~h}$ time bins) for tagged Atlantic cod Gadus morhua released at deep boulder reefs in 2002 (A) and 2004 (B). Error bars: $\mathrm{SE}$

All fish that exhibited high site fidelity made at least 1 departure from the range of the receiver at the DBRs where they were released (Table 2). The majority of departures for 9 of these fish were $<2 \mathrm{~h}$ in duration. A comparison of the number of departures per fish among the 3 DBRs indicated no differences (ANOVA, $F_{2,7}=0.08, \mathrm{p}=0.475$ ). The maximum duration of departures ranged from 1 to $151 \mathrm{~h}$, while the mean duration per departure was $1.2 \mathrm{~h}(\mathrm{SD}=0.57)$. A comparison of the mean hours per departure among DBRs indicated no differences (Kruskal-Wallis, $H_{2}=2.68, \mathrm{p}=0.260$ ).

Tagged cod did not show clear diurnal movement patterns during this sampling period either (Fig. 3B). All fish were released on the seafloor between 11:00 and 22:00 $\mathrm{h}$ GMT. The records for 20 of the tagged fish were evenly distributed between day and night. Among fish that exhibited high site fidelity, the proportion of $1 \mathrm{~h}$ time bins recorded during daylight (mean =
0.515) and night (mean $=0.485$ ) was comparable. No fish were recorded solely during either the daylight or the night hours, though 5 fish were recorded more frequently during the daylight, and 2 fish were recorded more frequently at night. A comparison of the day/night detection ratio among the 4 receivers indicated no differences in diel movement patterns at any of the 4 DBRs (Kruskal-Wallis, $H_{2}=1.89, \mathrm{p}=0.389$ ).

\section{A comparison between sampling periods}

The data from the 2 sampling periods were not significantly different with respect to any of the metrics quantified during this study. Our hypothesis that the site fidelity of fish tagged in the summer months $($ mean $=38 \%$, SD $=0.44$ ) would be greater than the fidelity of fish tagged over the winter months (mean $=47 \%, \mathrm{SD}=0.39$ ) was not confirmed (1-tailed Mann-Whitney, $W=1164, \mathrm{p}>$ 0.05). Further, neither the total number of departures per fish (ANOVA, $F_{1,22}=0.05, \mathrm{p}=0.261$ ) nor the mean duration per departure per fish (MannWhitney, $W=202.0, \mathrm{p}=0.7896$ ) were significantly different between sampling periods. Finally, the ratio of day/night detections did not differ significantly between sampling periods (MannWhitney, $W=841, \mathrm{p}=0.255)$.

\section{DISCUSSION}

Atlantic cod Gadus morhua exhibit a wide spectrum of movement behaviors, from 'resident' at a variety of spatial scales to migrations over 1000s of kilometers, and these behaviors vary both across the geographic range of the species as well as within spatially distinct local populations (Robichaud \& Rose 2004). However, important questions remain regarding the precise role of local environmental conditions, such as seafloor habitat, in the mediation of cod movements (Cote et al. 2002, Lindholm \& Auster 2003, Neat et al. 2006). In the present study, the use of acoustic telemetry allowed us to characterize the movement of cod at a small spatial scale and with respect to a discrete seafloor habitat. The results indicate that $35.4 \%$ of all tagged cod exhibited high site fidelity to the DBR where they were caught and released, while $50.8 \%$ appeared to depart the area rapidly following release. The fidelity of the remaining tagged fish $(13.8 \%)$ fell somewhere between these 2 extremes.

High site fidelity at discrete DBRs was not surprising. In a topographic context, DBRs are generally isolated 
within an otherwise homogenous low-relief environment. Similar to tropical coral reefs, there is often a halo of low-relief biogenic structure located around the perimeter of the DBRs, including patches of the burrowing anemone Cerianthus borealis and a variety of sessile erect sponges, all of which attract prey and predator alike. The DBR complex, consequently, provides a comparatively prey-rich environment for an adult cod with respect to the surrounding landscape.

Auster \& Lindholm (2005) characterized cod as both transient and resident components of DBR fish fauna, based on direct observations of fish moving on and off reefs. These observations were made during summer months, and are consistent with patterns in the movement of cod we tagged in 2002. During this period, the temperature of the water column is highly stratified in the study area (Ward 1995). This thermal stratification may represent a barrier to the movement of poikilothermic organisms such as fish (Bond 1996), and therefore may partially explain the fidelity we recorded to DBRs during the summer months.

The comparable site fidelity of cod during the winter months was not expected. Our prediction of reduced site fidelity during these months was based on an anticipated increase in temperature-mediated fish movements resulting from seasonal changes in water temperature as well as the potential for participation of adult fish in seasonal spawning aggregations away from the DBRs. Though data on the effect of temperature on cod movement are contradictory (Brown et al. 1989, Winger et al. 2000), seasonal changes in the movement behavior of cod have been well documented (Clark \& Green 1990, Comeau et al. 2002, Cote et al. 2004). Very little is known about cod behavior in the winter months within the study area, when the water column is vertically mixed (Ward 1995) and direct observations are limited.

Cod in southern New England spawn from November to May (O'Brien et al. 1993). Anecdotal information on cod spawning in the vicinity of the study area (Anonymous 2006) suggests local spawning may occur as early as December or as late as May. The total length of all fish tagged in this study exceeded the estimated $38 \mathrm{~cm}$ size at first maturity for the region (Mayo \& O'Brien 2000), and thus participation of tagged fish in spawning aggregations was a possibility. Fish that exhibited high site fidelity to DBRs either did not spawn during the study period, or potentially spawned at the DBR of their release. Several fish departed the array in November/December for what could have been spawning activities, though only Tag 12 returned to the DBR of its release.

Many tagged cod were recorded briefly after their release before disappearing for the duration of the study (Fig. 2). We can only speculate regarding expla- nations for their movements. It is possible that these fish were sedentary residents with daily ambits that included, but were not limited to, the DBRs where we caught and tagged them (Auster \& Lindholm 2005). It is more likely that we tagged transient individuals during their brief visitations to a DBR, and they subsequently dispersed. Another potential explanation for the abrupt departure of a fish from the receiver array is fishing activity. Recreational party vessels were common visitors to the DBRs during the course of the study, particularly in the summer months. On numerous occasions during the fish tagging operations, we observed vessels anchoring at DBRs immediately following our departure from the area.

Finally, loss of fish from the acoustic record could be attributed to the technical limits of detection of tagged fish. We assumed that there would be minor fluctuations in range and detection probabilities of tagged fish by the receivers due to changes in local oceanographic conditions over time (Welch et al. 2004). However, such variation likely had little effect on the overall patterns in our results. Individual fish would not have stayed just outside the envelope of detection around receivers. Observations of cod suggest they commonly move along the axis of DBRs and similar high-relief features (authors' pers. obs.). Given that we recorded presence-absence from the receiver locations over periods of days, the likelihood of not detecting a tagged fish in the area of a reef for an extended period after release is extremely small.

Observational data on cod behavior off-shore in the western GoM have been largely limited to daylight hours. Documentation of diel patterns in cod movement elsewhere varied depending on fish age and the time of year, with studies showing clear nocturnal behavior (Hawkins et al. 1974), diurnal movements with nocturnal resting (Clark \& Green 1990, Løkkeborg \& Fernö 1999), activity throughout the diel cycle (Mattson 1990), and activity throughout the diel cycle accompanied by increases in nocturnal behavior (Cote et al. 2002). We found no difference in diel behavior based on detections of tagged cod between the summer and winter sampling periods (Fig. 3). In both periods, the movements of those fish recorded by the receiver array for more than a few days were evenly distributed throughout the diel cycle. This transmitter detection pattern is consistent with direct observations of cod that exhibited continuous swimming behavior regardless of the time of day (authors' pers. obs.).

Spatial management approaches for the conservation of wild fish populations are one way to reduce fishing mortality, bycatch, and impacts to important habitats. Such approaches can focus on conservation of size-class composition, reproductive adults, genetic diversity, nursery or adult habitats, important species 
interactions, as well as a variety of other attributes (Auster \& Shackell 2000, National Research Council 2001, 2002, Lindholm \& Auster 2002, Sobel \& Dahlgren 2004). Regardless of the management goal, a common challenge for implementing such approaches is predicting the optimal location and size of management areas based on habitat associations and movement patterns of the species of interest (Lindholm \& Auster 2002, Link \& Demarest 2003). The results of our study indicate that spatial boundaries encompassing both the DBRs themselves as well as the halos around their perimeters could capture up to $35.4 \%$ of a local 'resident' group of cod in surprisingly small areas.

This work has important implications for both fishery management measures as well as those focused on conservation of biological diversity. Understanding the spatial dynamics of populations with both resident and transient components linked to particular habitats can lead to unique management measures and alternatives (e.g. allowing fishing in areas that target transient individuals only). Further, habitats with resident animals may capture representative examples of communities and maintain species interactions and serve as better sites for marine reserves that focus on conservation of diversity. Nevertheless, more work on patterns of connectivity between habitats, both within intra- and inter-annual time frames across a broader range of size classes and species will be needed to improve management for both the conservation and sustainable use of marine biological diversity in general and marine fishes in particular.

Acknowledgements. Support for the project was provided by the Stellwagen Bank National Marine Sanctuary and the National Undersea Research Center at the University of Connecticut. The views expressed herein represent those of the authors and do not necessarily reflect the views of the NOAA or any of its sub-agencies. We are grateful to S. Kibner for key field support throughout the project. We also thank K. Kibner, J. Noonen, J. Crawford, C. Case, and L. Norwood for assistance in catching fish, and to the crews of the RV 'Connecticut' and the FV 'Christopher Andrew' for assistance in deploying and recovering equipment. $M$. Thompson created Fig. 1. This work was conducted under permit from Stellwagen Bank National Marine Sanctuary (SBNMS-2002-053) and Protocol SSX 0501 from the Institutional Animal Care and Use Committee at the University of Connecticut.

\section{LITERATURE CITED}

Anonymous (2006) Ecosystem relationships in the Gulf of Maine-combined expert knowledge of fishermen and scientists. Northeast Atlantic Marine Alliance Collaborative Report 1:1-16

Auster PJ, Lindholm J (2005) The ecology of fishes on deep boulder reefs in the western Gulf of Maine. In: Godfrey J, Schumway $\mathrm{S}$ (eds) Proc Am Acad Underwater Sci. Connecticut Sea Grant, Groton, CT, p 91-109
Auster PJ, Shackell NL (2000) Marine protected areas for the temperate and boreal Northwest Atlantic: the potential for sustainable fisheries and conservation of biodiversity. Northeast Nat 7:419-434

Bond CE (1996) Biology of fishes. Saunders College Publishing, New York

Brown JA, Pepin P, Methven DA, Somerton DC (1989) The feeding, growth, and behaviour of juvenile cod, Gadus morhua L., in cold environments. J Fish Biol 35:373-380

Clark DS, Green JM (1990) Activity and movement patterns of juvenile Atlantic cod, Gadus morhua, in Conception Bay, Newfoundland, as determined by sonic telemetry. Can J Zool 68:1434-1442

Collette B, Klein-MacPhee G (eds) (2002) Bigelow and Schroeder's fishes of the Gulf of Maine. Smithsonian Institution Press, Washington, DC

Comeau LA, Compana SE, Chouinard GA (2002) Timing of Atlantic cod (Gadus morhua L.) seasonal migrations in the southern Gulf of St. Lawrence: interannual variability and proximate control. ICES J Mar Sci 59:333-351

Cote D, Ollerhead LMN, Gregory RS, Scruton DA, McKinley RS (2002) Activity patterns of juvenile Atlantic cod (Gadus morhua) in Buckley Cove, Newfoundland. Hydrobiologia 483:121-127

Cote D, Moulton S, Frampton PCB, Scruton DA, McKinley RS (2004) Habitat use and early winter movements by juvenile Atlantic cod in a coastal area of Newfoundland. J Fish Biol 64:665-679

Garrison L, Link J (2000) Dietary guild structure of the fish community in the northeast United States continental shelf ecosystem. Mar Ecol Prog Ser 202:231-240

Hawkins AD, MacLennan DN, Urquhart GG, Robb C (1974) Tracking cod Gadus morhua L. in a Scottish sea loch. J Fish Biol 6:225-236

Hunt JJ, Neilson JD (1993) Is there a separate stock of Atlantic cod in the western side of the Bay of Fundy? North Am J Fish Manage 13:421-436

Hunt JJ, Stobo WT, Alameida F (1999) Movement of Atlantic cod, Gadus morhua, tagged in the Gulf of Maine area. Fish Bull 97:842-860

Jackson JB, Kirby MX, Berger WH, Bjorndal KA and 15 others (2001) Historical overfishing and the recent collapse of coastal ecosystems. Science 293:629-638

Lear WH (1999) History of fisheries in the northwest Atlantic: the 500-year perspective. J Northwest Atl Fish Sci 23: $41-73$

Lindholm J, Auster PJ (2002) Marine protected area design: toward a generalized life history approach. In: BondrupNielsen S, Munro NWP, Nelson G, Willison JHM, Herman TB Eagles $P$ (eds) Managing protected areas in a changing world. SAMPAA, Wolfville, p 1126-1136

Lindholm J, Auster PJ (2003) Site utilization by Atlantic cod (Gadus morhua) in off-shore gravel habitat as determined by acoustic telemetry: implications for the design of marine protected areas. Mar Technol Soc J 37:27-34

Lindholm J, Auster PJ, Ruth M, Kaufman L (2001) Modeling the effects of fishing and implications for the design of marine protected areas: juvenile fish responses to variations in seafloor habitat. Conserv Biol 15:424-437

Link JS, Demarest C (2003) Trawl hangs, baby fish, and closed areas: a win-win scenario. ICES J Mar Sci 60:930-938

Løkkeborg S, Fernö A (1999) Diel activity and food search behaviour in cod, Gadus morhua. Environ Biol Fish 54: 345-353

Mattson S (1990) Food and feeding habits of fish species over a soft sublittoral bottom in the Northeast Atlantic. I. Cod (Gadus morhua L.) (Gadidae). Sarsia 75:247-260 
Mayo R, O'Brien L (2000) Status of fishery resources off the northeastern United States-Atlantic cod. NOAA Fisheries, Northeast Fishery Science Center, Woods Hole. Available at: www.nefsc.noaa.gov/sos/spsyn/pg/cod/

Mayo R, Terciero M (2005) A report of the stock assessment workshop (SAW) northern and southern demersal working groups assessment of 19 northeast groundfish stocks through 2004, 2005 Groundfish Assessment Review Meeting (2005 GARM), 15 to 19 August 2005. Northeast Fisheries Science Center Reference Document 05-13, Northeast Fisheries Science Center, Woods Hole, MA

National Research Council (2001) Marine protected areas: tools for sustaining ocean ecosystems. National Academy Press, Washington, DC

National Research Council (2002) Effects of trawling and dredging on seafloor habitat. National Academy Press, Washington, DC

Neat FC, Wright PJ, Zuur AF, Gibb IM, Gibb FM, Tulett D, Righton DA, Turner RJ (2006) Residency and depth movements of a coastal group of Atlantic cod (Gadus morhua L.). Mar Biol 148:643-654

O'Brien L, Burnett J, Mayo RK (1993) Maturation of nineteen species of finfish off the northeast coast of the United States, 1985-1990. NOAA Tech Rep, NMFS (113), US Department of Commerce, NOAA, National Marine Fisheries Service, Washington, DC

Perkins HC, Chenoweth SB, Langton RW (1997) The Gulf of Maine Atlantic cod complex, patterns of distribution and movement of the Sheepscot Bay substock. Bull Natl Res

Editorial responsibility: Kenneth Sherman, Narragansett, Rhode Island, USA
Inst Aquac (Jpn) Suppl 3:101-107

Robichaud D, Rose GA (2001) Multiyear homing of Atlantic cod to a spawning ground. Can J Fish Aquat Sci 58: $2325-2329$

Robichaud D, Rose GA (2004) Migratory behavior and range in Atlantic cod: inference from a century of tagging. Fish Fish 5:185-214

Serchuk FM, Wigley SE (1992) Assessment and management of the Georges Bank cod fishery: an historical review and evaluation. J Northwest Atl Fish Sci 13:25-52

Sobel J, Dahlgren C (2004) Marine reserves: a guide to science, design and use. Island Press, Washington, DC

Sokal RR, Rohlf FJ (1995) Biotelemetry, 3rd edn. W.H. Freeman, New York

Valentine PC, Unger T, Baker J (2003) Sun-illuminated sea floor topography and backscatter intensity of the Stellwagen Bank National Marine Sanctuary region off Boston, Massachusetts. U.S. Geological Survey Geologic Investigations Series, Map I-2676-C, scale 1:60000, U.S. Geological Survey, Woods Hole, MA

Ward N (1995) Stellwagen Bank. Downeast Books, Camden

Welch DW, Ward BR, Batten SD (2004) Early ocean survival and marine movements of hatcher and wild steelhead trout (Oncorhynchus mykiss) determined by an acoustic array: Queen Charlotte Strait, British Columbia. Deep-Sea Res Part II 51:897-909

Winger PW, He P, Walsh SJ (2000) Factors affecting the swimming endurance and catchability of Atlantic cod (Gadus morhua). Can J Fish Aquat Sci 57:1200-1207

Submitted: October 4, 2006; Accepted: February 5, 2007 Proofs received from author(s): June 22, 2007 